\title{
Diablotexto
}

\section{Redes de sororidad transoceánicas e identidad iberoamericana en dos periodistas asturianas: Eva Canel y María Luisa Castellanos}

Transoceanic sorority and Iberoamerican identity in two Asturian journalists: Eva Canel and María Luisa Castellanos

\section{Daniel González Gallego UNIVERSIDAD DE CÓRDOBA}

Resumen: El presente artículo estudia la producción e implicación americanista de dos autoras asturianas casi opuestas: Eva Canel y María Luisa Castellanos. El estudio propone una aproximación a ambas mujeres desde ciertas directrices básicas de los estudios transatlánticos, insertándolas en un espacio de diálogo transoceánico con otras mujeres intelectuales de España y América en el periodo finisecular. Para ello, se trazará un recorrido a través de tres ejes fundamentales: las doctrinas territoriales de colonialismo y regionalismo asturiano, la cuestión migratoria femenina de España a las Américas y la promoción y difusión de mujeres españolas e hispanoamericanas entregadas al ámbito humanístico y periodístico.

Palabras clave: periodo finisecular, periodismo, literatura, feminismo, estudios transatlánticos

\begin{abstract}
This paper examines Eva Canel and María Luisa Castellanos's written work and Americanist involvement, by which both women held some opposing political and social views. This proposal develops through the basics of transatlantic studies and attempts to relocate both authors to a Spanish and Latin American network of female intelectuals in the turn of the century. The analysis is conducted through three main notions: colonialism and Asturian regionalism, Spanish female migration and the promotion and dissemination of Spanish and Latin American female writers and journalists.
\end{abstract}

Key words: turn of the century, journalism, literature, feminism, transatlantic studies 


\section{Contextualización, objetivos y algunos acercamientos previos}

El periodo finisecular supone una época convulsa repleta de acontecimientos históricos que implicaron, en último término, el fin del imperialismo español. En el centro de este maremágnum político, el colectivo femenino cuestiona el modelo vigente del ángel del hogar y comienza a integrarse paulatinamente en la vida pública. Además, el inconmensurable flujo migratorio de españolas a América contribuye a poner de relieve, nuevamente, la cuestión femenina. Muchas de estas mujeres viajan acompañando a sus maridos, aunque las más privilegiadas social e intelectualmente logran, en la medida de lo posible, establecerse en el continente americano con el objetivo de emprender una nueva vida profesional.

En este contexto se sitúan las dos autoras objeto de estudio: Eva Canel contrajo matrimonio a los catorce años con Eloy Perillán y Buxó, periodista y dramaturgo vallisoletano que, debido a sus ideas republicanas, fue desterrado a Montevideo. Posteriormente, Canel viajó a la capital uruguaya para reunirse con él y, tras enviudar en 1889, decidió establecerse en Cuba. Por otro lado, María Luisa Castellanos nació en los años más delicados del periodo decimonónico y, desde muy joven, comenzó a publicar artículos en el periódico El Pueblo de Asturias. Tras contraer matrimonio con Antonio Alonso Inguanzo en 1921, los recién casados se trasladaron a México, donde Castellanos siguió compatibilizando la faceta periodística con su labor docente y su compromiso feminista. A pesar de que ambas autoras coinciden en ciertos planteamientos, especialmente en su defensa a la mujer y su compromiso con la cultura latinoamericana, sus fundamentos ideológicos son casi opuestos ${ }^{1}$, lo cual acrecienta el interés en un estudio comparatista.

Son múltiples los objetivos planteados para este estudio, como lo son los encuadres teóricos requeridos para alcanzarlos. Se pretende realizar un

\footnotetext{
1 Tras enviudar, Canel abandona el ideario republicano que adoptó de su marido y vira radicalmente hacia el conservadurismo, declarándose abiertamente monárquica, coqueteando con el carlismo e incluso, paradójicamente, definiéndose como "antifeminista" (Kenmogne, 1995: 56). Castellanos, en cambio, es republicana y defiende causas como la abolición de la tauromaquia y los procesos antifascistas.
} 
sucinto recorrido por las producciones escritas de Canel y Castellanos en prensa periódica y literatura para, posteriormente, reflejar sus impresiones sobre tres cuestiones fundamentales: las reacciones y consecuencias del dominio colonial en Hispanoamérica, así como la implicación del territorio asturiano en tal proceso; la emigración, especialmente en lo que concierne a la mujer viajera; y, por último, su compromiso intelectual en valorar y dar a conocer a otras compañeras del mundo editorial a ambos lados del Atlántico.

Los estudios previos en torno a Eva Canel (Simón Palmer, 1992 y 2004; Kenmogne, 1995; Ferrús Antón, 2011a y 2011b) y a María Luisa Castellanos (García Galán, 2011 y 2013) introducen satisfactoriamente algunas de las cuestiones que se tratarán en las sucesivas páginas. El presente trabajo apunta a contribuir a la investigación y a la reincorporación de ambas mujeres a la primera línea de los estudios literarios, así como reivindicar su lugar en las redes de sociabilización e institucionalización transatlánticas articuladas por las escritoras de final de siglo. Con el propósito de integrar a Canel y Castellanos en este sistema, se plantea un aparato teórico articulado sobre los enfoques académicos de hispanismo, latinoamericanismo e iberoamericanismo (Pinedo, 2018; Resina, 2018), trasladándonos al ámbito de los estudios transatlánticos y la situación femenina ante el entramado literario y cultural de los siglos XIX y XX (Ortega, 2003; Macciuci, 2018). Los apuntes en torno a ambas periodistas permitirán habilitar nuevos enlaces para la historiografía literaria femenina y promover posteriores vías de investigación en torno a otras escritoras poco conocidas que, hoy por hoy, pueden denominarse mujeres transhemisféricas.

\section{Perspectivas hispanísticas y mujeres viajeras decimonónicas}

El primer reto que plantea el estudio de ambas periodistas recae en la complejidad de sus contextos históricos: Canel vivió en primera persona las controversias de los últimos años de la España colonial y el Desastre de Cuba, mientras que Castellanos experimentó las consecuencias de este imperialismo y, años después, del estallido de la Guerra Civil Española. Los puentes que ambas mujeres tendieron entre España y América Latina aducen ciertas 
contradicciones ocasionales que, a pesar de todo, poseen una justificación teórica al margen de juicios críticos e ideológicos. En esta problemática entran en vigor diferentes prismas para el estudio cultural de ambos territorios que, a pesar de ser a menudo intercambiables, muestran sutiles diferencias. Nos referimos a los términos hispanismo, latinoamericanismo e iberoamericanismo. Al primero, probablemente el más sencillo de delimitar, Pinedo (2018: 84-89) le atribuye un triple significado como campo de estudio, identidad histórica, y defensa conservadora del ideario cultural. La disciplina académica comprende un conglomerado de identidades y manifestaciones culturales sujetas a una misma lengua, religión y cultura; constituyendo así un argumento recurrente para la asunción del continente americano como una extensión territorial del imperio español. Esta ontología panhispánica, por tanto, hace que hispanismo y latinoamericanismo sean inseparables (Pinedo, 2018: 84). Aquí se halla una interesante paradoja, y es que la defensa de esta cultura, que nace de un "sentido heroico del pasado español" (Pinedo, 2018: 88), pasa por la apropiación de lo intrínsecamente latinoamericano, constituyendo en sí misma un acto colonizador. El filtro de lo hispánico deriva en un occidentalismo interiorizado en el que, tal y como apunta Ferrús Antón a propósito de la narrativa de Canel, lo continental se sobrepone a lo nacional eliminando toda especificidad cultural del territorio conquistado (2011a: 229). Sin embargo, el relato histórico del proceso (des)colonizador, abordado desde una narrativa pacífica y armónica, ha contribuido a largo plazo a la devaluación del hispanismo original, ya que el desplazamiento de la cultura latinoamericana hacia los márgenes ha otorgado a esta literatura un mayor interés como objeto de estudio académico:

[T] he study of Spain, its literature, and its history - its literary history - may have been displaced, globally, by the study of Latin America and non-literary forms of cultural production, but it remains to be seen what the displacement actually signifies (Epps y Fernández Cifuentes, 2005: 19).

Esta alteridad nace por la asimilación del discurso histórico hegemónico que apela a la fraternidad hispanoamericana basándose en una "vaga idea de progreso", por lo que se "tiende a suponer que el proceso histórico, aunque 
plagado de conflictos, acaba resolviéndolos en una universalidad en que las contradicciones se reconcilian en armonías estables" (Resina, 2018: 65). En este caso, la concepción del hispanismo como identidad cultural termina por reconfigurarse para así contribuir a la unión iberoamericana:

El hispanismo, en cuanto mediación cultural de esta historia de homogeneización, construye una imagen armonizada de lo que fue un proceso extraordinariamente violento, a la vez que acoge su resultado. En este sentido, puede decirse que el hispanismo es una postideología. (Resina, 2018: 66)

Resina propondría, por consiguiente, una reformulación de los estudios hispánicos bajo el término iberoamericanismo, que establecería "criterios valorativos sin recaer en la tentación de definir un canon nacional, hemisférico o mundial" que, por otra parte, "tampoco está hecho para sustentar la gloria de las naciones o del idioma" (2018: 75). En este sentido, lo iberoamericano propondría, teóricamente, superar las "líneas demarcatorias ligadas a la historia de América Latina, al pasado colonial y al discurso eurocentrista" (Macciuci, 2018: 114) que son evocadas por las denominaciones de lo hispánico y lo latinoamericano.

En una primera aproximación al término, la definición de estudios transatlánticos resulta compleja, especialmente en coexistencia con otros aparatos teóricos previamente considerados como la literatura poscolonial. Las dinámicas de la otredad, las fronteras y las construcciones fragmentarias del sujeto permanecen vigentes en este enfoque. Los estudios transatlánticos, por su parte, sugieren un mayor alcance:

Esa nueva perspectiva trata de definir la especificidad de la identidad latinoamericana desde un punto de vista más amplio y certero. Los cruces transatlánticos suponen un elemento fundamental de los procesos de fundación identitaria tanto de la exmetrópoli como de los países americanos. [...] La pérdida de la versatilidad con las independencias de América Latina no acabó con las relaciones transoceánicas, pero sí modificó su sesgo. (Capote Díaz y Esteban, 2017: 11)

Esta mirada transoceánica propone "una trama teórico-práctica de interacciones entre Europa, especialmente España, y las Américas nuestras" (Ortega, 2003: 115). Lo que desmarca a este postulado de las lecturas postcoloniales previas es que la tradicional dialéctica conquistador-conquistado fluye de un modo bidireccional y recíproco, por lo que "no siempre el sujeto 
colonial ilustra la victimización sino que, muchas veces, es capaz de negociar sus propios márgenes" (Ortega, 2003: 114-115). Algunos de los ejes en los que se articula esta mirada ya han sido tratados por la teoría literaria, tales como "las representaciones del sujeto atlántico y la reescritura del escenario colonial, la construcción del Otro en el relato de viaje, la hibridez de la traducción, el tránsito de ida y vuelta de los exilios y las vanguardias" (Ortega, 2003: 115). No obstante, nuestro cometido es deconstruir, desde la amplitud del enfoque transoceánico, la ya superada barrera entre lo peninsular y lo americano para afrontar una lectura iberoamericanista de la mujer de letras, tanto en su producción escrita como en los entornos sociales y editoriales en los que se desarrolla personal y profesionalmente.

Sobre esta mujer literata y su misión en América Latina ya reflexionó Soledad Acosta de Samper en 1895, recogiendo percepciones europeas que son, en su mayoría, arcaicas y simplistas. Sin embargo, la escritora ratifica una visión muy distinta entre los hispanoamericanos y desliza una sutil crítica al dominio colonial:

El hispanoamericano, más adelantado en estas cosas que el español -su antepasado-, ve en la mujer algo más que "una virgen en una iglesia". Se ha notado que en todas las repúblicas que se formaron después de la independencia, se ha tratado desde su fundación de dar á la mujer una educación mejor y un papel más amplio en la vida social. Los gobiernos han hecho grandes esfuerzos para redimirnos de la situación secundaria, y no diremos secundaria sino ínfima, á que nos condenaban las costumbres coloniales, hijas de las españolas. (Acosta de Samper, 1895: 382-383)

Junto a estas líneas, la obra de Acosta de Samper recoge un exhaustivo inventario bio-bibliográfico de mujeres europeas, animando a sus lectoras a tomarlas como posibles referentes. Los cruces transatlánticos, que se realizan de manera indirecta a través de los numerosos perfiles femeninos presentados, llevan implícito un viaje metafórico que, para gran parte de las mujeres presentadas, constituyó una realidad. El motivo del viaje supone un enlace entre escritoras, especialmente en el periodo decimonónico en el que las narrativas de exploración son tendencia literaria. Sus travesías y percepciones de los nuevos territorios visitados proporcionan a estas mujeres, además de una impagable y enriquecedora experiencia vital e intelectual, medios para la reflexión sobre su alteridad, sobre los infinitos horizontes literarios esbozados Diablotexto Digital 8 (2020), 57-78 
más allá de las fronteras de su patria y la posibilidad de trazar redes de sororidad literaria mediante las que afianzar la interacción cultural entre España y América. Igualmente, en el caso concreto de Asturias, el incremento exponencial de la emigración femenina en los siglos XIX y XX invita a estudiar este proceso como un condicionante sociocultural de estas lecturas transatlánticas. También se diluye de esta manera el estereotipo literario del inmigrante masculino, que posee un correlato con la mujer que le espera al otro lado del océano y es víctima de la ausencia (García Galán, 2011: 192). La travesía transatlántica supone, en materia retórica, una nueva subjetividad femenina a nivel social y literario, reconstruida desde esa alteridad experimentada en el tránsito entre las dos orillas. Por tanto, estas conexiones transoceánicas componen un instrumento esencial para el progreso simultáneo y paralelo entre feminismo y literatura:

\footnotetext{
En las redes sororales, el desorden sexo-genérico que tanta ansiedad causaba en el imaginario masculino se volvió un espacio productivo para cuestionar viejas dicotomías y para crear nuevas ficciones de identidad. Las escritoras del siglo XIX usaron los sistemas de religación para hacer del feminismo una conversación transatlántica resemantizando en el proceso las preocupaciones, figuras y topoi que circularon por las redes masculinas. (Peluffo, 2015: 221)
}

Estos procesos de resemantización a los que alude Peluffo no constituirán una moda literaria pasajera, sino que representarán vectores siempre presentes en la producción y el consumo de conocimiento (Meléndez, 2015: 247) y, lo más importante, mecanismos mediante los que la hermandad literaria femenina genera un espacio transnacional desde el que emprender diversas estrategias ideológicas, políticas e identitarias que sitúen a la mujer en primera línea de la vida pública (Fernández, 2015: 13).

\section{Postideología hispánica y cartografías personales en Eva Canel (Coaña,} 1857 - La Habana, 1932)

Cuando Eva Canel narra su primer viaje a América Latina en el relato "A bordo del Aconcagua", afirma que "los españoles tenemos la fea costumbre de burlarnos de todo cuando por vez primera salimos de nuestra patria. Pero [...] á la segunda somos más justos y menos imprudentes" (1899, I: 20). Como si de 
una predicción se tratase, la coañesa nunca imaginaría que este sería su mismo caso, y mucho menos que su fortísima implicación patriótica le brindase, entre ambas orillas del Atlántico, éxitos y controversias a partes iguales. Sus posicionamientos conservadores contra la insurrección cubana y el divorcio, entre otros temas, le generaron numerosos seguidores y detractores a lo largo de su vida. Durante su estancia en América, las posiciones de Canel oscilaron entre lo tradicional y lo progresista, antojándose a menudo contradictorias y trasluciendo un probable interés en ganarse a su público adaptando su discurso para cada ocasión (Barcia Zequeira, 2001: 241). Sin detenernos demasiado en las explicaciones lógicas a estos bruscos virajes ideológicos de Canel, diremos que la crisis del 98 en Cuba es lo que marca un punto de inflexión en su percepción de América Latina. Tan solo dos años antes, en el Casino Español de México, Eva Canel respondía agresivamente al discurso del senador estadounidense John Sherman, justificando el dominio español en Cuba y la posición del capitán Valeriano Weyler, a quien apoyaba. La visión caneliana es imperialista hasta el punto en que la nacionalidad cubana termina por difuminarse bajo la identidad española:

\footnotetext{
Y esto lo declaró un cubano, señores, no un peninsular. "Aumentaron las cargas públicas y se dieron a los españoles", dicen Estrada y Sherman. A los españoles sí, digo yo; no faltaba más sino que se diesen a los japoneses. Pero se dieron a los españoles sin distinción de provincias, lo mismo cubanos, que madrileños, que catalanes, llevando la mejor parte los primeros. (Canel, 1896: 7)
}

Canel abandona la isla unos años después, "llorando casi sin solución de continuidad" (Simón Palmer, 1992: 300). De este varapalo se hicieron eco varios medios de prensa: "no quiere permanecer en Cuba desde el momento que ondee allí la bandera norteamericana" (Los Debates, 1898: 2). Al ver frustrado su compromiso patriótico inicial, suavizó su postura y abogó por una unión iberoamericana (Sánchez Dueñas, 2013: 262) en la que la imagen de España fuese mejor valorada por los americanos. De este modo, la asturiana se desvinculaba de un hispanismo supremacista que justificó en uno de sus últimos discursos antes de enfermar:

¡Ah! Mis compatriotas de Cuba no me conocen, debiendo conocerme tanto y es que mis antiguos compatriotas de Cuba me han visto únicamente la faz del patriotismo 
exaltado por las circunstancias, pero nada saben de mi patriotismo sereno, tranquilo, consciente de todos los deberes, de todos los respetos, y de todos los sacrificios. (Canel, 1916a: 6)

Después de todas las controversias vividas y de haber reconducido su pensamiento, Canel llega a admitir la especificidad del continente anteriormente negada: "eran hispanoamericanos, no eran españoles" (Canel, 1916a: 6). A pesar de sus continuos escándalos, su inagotable labor como americanista le otorgó el cariño y reconocimiento de cierta parte de la población autóctona, que llegó a considerarla erróneamente cubana. Las rectificaciones solicitadas por la propia autora a este respecto se recibían con cierta sorpresa, dada su esmerada, aunque en ocasiones cuestionable, defensa de América:

\begin{abstract}
Me veo en el caso de rectificar que la chispeante escritora no es cubana, sino española neta, porque nació en Asturias. Por ello satisface más su americanismo sin ambajes [sic], enérgico, resuelto y entusiasta como no lo sintieron quizás nunca muchos americanos [...]. Si todos los españoles literatos pensaran respecto de nosotros lo que piensa Doña Eva, y nos quisieran como nos quiere ella, la unión ibero-americana resultaría pronto un hecho realmente positivo, y los bienes que de él se originarían para América y España, serían incalculables. (Picón-Febres, 1898: 124, nota al pie)
\end{abstract}

Por otro lado, las evocaciones a Asturias en sus relatos constituyen un interesante cauce de miradas recíprocas entre España y América que, junto a su constante exhibición de españolismo, sugiere uno de los ejes fundamentales de sus narraciones (Ferrús Antón, 2011b: 38-39). En el contexto de la celebración de la fiesta de Covadonga en la colonia asturiana, Canel dice desear un ideal de fraternidad hispanoamericano, a pesar de que emplee como argumento la lengua común:

Aquel arranque de unión Ibero Americana que á mí me pareció salir del alma, unión á la cual he consagrado luchas y desvelos de mi pobrísima vida intelectual, me hizo entrever ese cielo de preponderancia que yo en mis sueños (también me permito soñar) ansío para la raza ibera. ¡América, Asia, África, España!... ¿Quién ha dicho que somos decadentes, cuando todavía nuestra lengua es la dueña del mundo? (Canel, 1894: 97)

Esta justificación, heredada de la concepción postideológica del hispanismo, se contradice con el planteamiento de unión, a pesar de que a ojos de Canel signifique un acto de concordia en el que celebrar el triunfo español y retrotraerse al mito de la Reconquista: 
Porque en la fiesta de Covadonga únense los socios de la beneficencia y los asturianos en general, sin distinción de clases, ni de partidos, ni de aspiraciones; se mezclan gozosos y entusiasmados y se apiñan todos a los pies de la regeneradora de España, lanzando el patriótico ixuxú ${ }^{2}$ de los astures: gloria in excelsis, de nuestra reconquista. (Canel, 1894: 153)

Sin embargo, la conexión Asturias-Cuba trae a colación otras cuestiones menos halagüeñas. El tránsito que resulta enriquecedor para Canel se convierte en un calvario para las inmigrantes asturianas menos privilegiadas, por lo que Canel denuncia las penurias que estas sufren a su llegada a la isla y apela así a su protección por parte de los hombres. Se trata de una visión transhemisférica y transversal, mediante la que visibilizar un problema social que concierne a las dos orillas. Igualmente, se manifiesta un condicionante de género que diferencia la experiencia transatlántica de hombres y mujeres:

Debieran ocuparse de esas mujeres que traen el propio origen que han traído ellos, y que por ser mujeres, destinadas a madres, tanto le importa a España como le importa a América, tanto a los españoles como a los cubanos, que esas mujeres sean correctas, que esas modestas inmigrantes persistan en mantenerse puras [...]. Tened la caridad de hacerles llevadera la vida, ya que no es senda perfumada; pensad que abandonaron su patria y sus hogares, menos autorizadas, por su sexo, de lo que estáis vosotros y cuanto hagáis en bien de la mujer, que tiene un sagrado derecho a vuestra tutoría, lo hacéis en beneficio de vuestros descendientes. (Canel, 1916b: 90) ${ }^{3}$

En cuanto a los enlaces profesionales entre España y América, Canel se dedica a esta labor fundamentalmente en la revista Kosmos (1904-1909), fundada por ella misma en Buenos Aires. A pesar de todo, las firmas femeninas son bastante escasas: su prima Luisa Lacal, Rosa de Altavilla, Carmen Rojo y Carolina Freyre de James son las más significativas. Otros actos de solidaridad y patronazgo por parte de Canel fueron los que tuvo con Concha Espina, a la que concedió una sección fija en Kosmos; con Mercedes Matamoros, a la que ayudó a publicar su novela Sensitivas (Simón Palmer, 1992: 302-304); y con Ernestina Méndez Reissig, que dedica a Canel un capítulo de su obra Lágrimas (1902: 64) y esta le aconseja, constructivamente, que emplee modelos castellanos de escritura, augurándole gran éxito como literata (Méndez Reissig, 1902: XIX).

\footnotetext{
${ }^{2}$ Interjección asturiana que expresa alegría o júbilo (Academia de la Llingua Asturiana, s.f.).

${ }^{3}$ El texto forma parte del artículo "La protección de la mujer. Obras, no palabras", publicado anteriormente en Asturias: revista gráfica semanal (28-11-1915).
}

Diablotexto Digital 8 (2020), 57-78 
Estos son solo algunos de los casos en los que Canel buscaba favorecer la institucionalización de jóvenes escritoras y periodistas que, al igual que ella tras el fallecimiento de su marido, padecían numerosas complicaciones para abrirse paso en el mundo profesional. En esta red femenina en la que inscribiríamos a Canel encontramos otras formas de promoción ligadas a su ámbito personal. Un buen ejemplo de ello es su amistad con tres importantes mujeres cubanas: Celia Delmonte, la poetisa Luisa Pérez de Zambrana y la periodista Domitila García de Coronado. Las tres, tal y como dice Canel al recibir su visita tras su regreso a Cuba, no habían sabido o querido olvidarla (Canel, 1916b: 25). En este caso, no podemos hablar de reseñas biobibliográficas estrictas como las que posteriormente observaremos en María Luisa Castellanos, sino que son recuerdos que componen "una cartografía de relaciones personales, en un mapa de contactos y afectos, donde el espacio se borra a favor de las personas" (Ferrús Antón, 2011b: 38). Sus amigas en Cuba son símbolos de su propia alteridad, representaciones de su vida personal y profesional a un lado y al otro del océano. A Luisa Pérez de Zambrana le dedica, incluso, un breve capítulo de su autobiografía:

\footnotetext{
Les hablé mucho de ella: me producía pena que mujeres cubanas instruídas [sic] y ricas no supiesen de la existencia de esta compatriota que debiera ser reliquia para todas, por haber dado brillo a la poesía [...]. [i]Cuántas cosas aprenderían muchas mujeres acompañando a Luisa Pérez de Zambrana, en esos paseos de una caridad íntima, ideal, aristocrática, mental, y oyéndole expresarse con el lenguaje clásico, puro, correcto que ya no emplean muchos hombres! (Canel, 1916b: 105-106)
}

De la misma manera retrata a la periodista y editora Domitila García de Coronado, responsable de la Academia de Tipógrafas: "esta querida amiga mía ha luchado como un titán por abrir y despejar esa profesión a la mujer cubana y lo ha conseguido" (Canel, 1916b: 238). Aunque estas cartografías literarias no sean abundantes ni explícitas, nos remitimos, para terminar, a uno de sus primeros artículos en prensa española. En él, Canel exigía una mayor participación femenina en los congresos literarios, aludiendo especialmente a su admirada Emilia Pardo Bazán y a la Baronesa de Wilson, amiga de la asturiana y madrina de su hijo Eloy Perillán Canel. De esta última destaca, precisamente, su contribución transoceánica: "sus obras referentes á la 
América latina, sus catorce años dedicados á viajar por el mundo de Colón, estudiando sus costumbres y su historia, son otros tantos títulos que deben llevarla á ocupar un lugar allí donde tengan representación sus letras" (Canel, 1887: 2). Con ello, Eva Canel dejó claro que, a pesar de sus visiones tradicionalistas, la promoción femenina en las letras formaba parte de un deber ético, humanístico y sororal digno de ser reivindicado.

\section{Las “escritoras americanas” de María Luisa Castellanos (Llanes, 1892 - Cuernavaca, 1974)}

Esta autora, nacida en el barrio de El Cuetu en Llanes, fue una mujer polifacética: su compromiso humanístico se extendió más allá de la literatura, llegando a dedicarse a otros ámbitos como el cine o la crítica de arte, además de sus disertaciones en torno al feminismo y otras causas revolucionarias. Se mudó con su marido Antonio Alonso Inguanzo a México en 1921, lugar donde se dedicó a la docencia sin abandonar completamente el periodismo (García Galán, 2013: 338). Aunque a partir de 1935 se establece en Madrid, abandonará poco después España ante la Guerra Civil, y permanecerá en México hasta su deceso en 1974. Las contribuciones de Castellanos se vertebran sobre tres ejes temáticos fundamentales: el feminismo, Asturias y leyendas o relatos históricos. En cierta manera, esta tríada se reitera en las observaciones de la llanisca en lo que concierne al territorio americano. Involucrada en la Unión de Mujeres de España y primera alumna oficial en la Facultad de Derecho de Oviedo, su ferviente activismo constituyó el primer intento de un organismo feminista autónomo en Asturias (García Galán, 2013: 644).

En cada una de sus aportaciones, Castellanos demostró un creciente interés humanístico en la literatura y otras disciplinas, como la música y la pintura. Sus principales preocupaciones coincidían con las de Eva Canel, aunque su recepción fue, por lo general, mucho más positiva y alejada de las polémicas. Consciente del escenario iberoamericano heredado del dominio colonial, las impresiones de Castellanos durante su primer año en México 
repararon especialmente en las reminiscencias peninsulares de la Ciudad de los Palacios:

Sea cualquiera la razón de llamar á la capital de la República Ciudad de los Palacios, es el caso que hay pocas calles en que no se observen suntuosos vestigios de la época colonial, ora en los palacios de inmensas portaladas, cuyo frontispicio ostenta un humilladero con la imagen de la Virgen, cual si estuviéramos en las provincias castellanas. (Castellanos, 1922: 25)

El artículo refiere también a un acto de homenaje que sorprende a la escritora por "el corto número de españoles presentes", y en el que se trata "con admirable tacto tema tan delicado como el de la independencia mejicana y la amistad de esta nación con España” (Castellanos, 1922: 25). La autora es prudente en la descripción de esta relación que, al igual que Canel, considera cordial. No obstante, incurre nuevamente en el "discurso nacionalista y conservador sobre la comunidad de raza, lengua, historia y cultura" (Vélez, 2007: 126) que se difundía a través de la unión iberoamericana, mediante el cual Castellanos concluye que "la Ciudad de los Palacios es España; lo es su lengua, su religión, sus costumbres" (1922: 25).

A ojos contemporáneos, es relativamente sencillo remitirnos al ideal nacionalista señalado por Vélez. En este ideal solidario se basa Castellanos al componer uno de sus textos centrales para hablar de la presencia asturiana en América. En su firma, Castellanos especifica que escribe este texto a bordo del barco Cristóbal Colón en pleno centro del Atlántico. Además, su publicación en 1928 supone cierta evolución en su percepción de América tras varios años viviendo en México, por lo que atribuye a esta alianza Asturias-América un principio altruista mutuo en el que las dos civilizaciones se enriquecen recíprocamente. Sin embargo, la justificación de Castellanos cae por su propio peso al incurrir en una visión feminista que, aun coincidiendo con algunas de sus percepciones, no resulta en absoluto progresista:

La labor colectiva de los españoles de América influye mucho en los caracteres del país. Las fiestas de nuestros centros regionales son honradas con la presencia de numerosas y muy principales familias americanas [...]. El carácter del americano que está en contacto con el asturiano, se hace más recio, más entero, más profundo y más entusiasta de España. A su vez el asturiano se identifica con América y toma de allí lo mejor de su carácter, lo más escogido de su carácter, bellas mujeres a quienes desposan. Pocos como el asturiano están llamados a formar la gran familia 
hispanoamericana, pocos como él que tengan tantos elementos raciales, materiales y morales, para inyectar la savia fecunda de su vida en el gran árbol de América, llámese ombú, cocotero, ahuehuete, palmera, tule o pirú. (Castellanos, 1928: 24-25)

La aprobación del mestizaje posee una doble lectura, en tanto que parece apoyar la unión racial aunque para ello se reduzca a la mujer a una simple tecnología reproductiva. Se trata de una afirmación que, hoy por hoy, sería cuestionable, aunque Castellanos no deja de defender en la misma forma a la mujer intelectual y al ángel del hogar como espectros complementarios de un feminismo común ${ }^{4}$. El discurso de raza, por otra parte, resulta similar al de Canel, por lo que el filtro hispánico sigue influyendo en este relato de la historia.

Esta acción se extendió, por consiguiente, a la consideración de la mujer inmigrante, para la que solicitaba auxilio junto a las integrantes de la Unión de Mujeres de España:

Al alzar mi voz al lado de damas de tanto prestigio y talento como nuestra Presidenta la Marquesa del Ter y la ilustre escritora socialista María de Lluria que pedían reivindicaciones femeninas y miradas de afecto y compasión hacia las mujeres de España, dediqué toda mi oración a hablar de la emigración femenina, de la necesidad que había de extender el radio de acción de las mujeres de España a las jóvenes repúblicas y fundar allí nuestras Delegaciones entre damas españolas y americanas que al fin son hijas de España - para que esas damas [...] acogiera[n] en su seno a las muchachas asturianas que van tras el señuelo de mayores ganancias y menos trabajo que en el país natal y caen víctimas del desamparo, de la miseria y de la inexperiencia, que son las peores consejeras y las que despeñan la sólida virtud de nuestras hermanas en los negros abismos del vacío. (Castellanos, 1919b: 11)

\section{La principal diferencia que encontramos a este respecto con Eva Canel}

es que Castellanos, además de sentenciar que las juntas de apoyo "deben

estar formadas por mujeres", no duda en apelar a la sororidad:

Nadie como nosotras para comprender el dolor del que sufre, para perdonar la afrenta del desdichado, para levantar al caído. [...]. Este es uno de los problemas que más me

\footnotetext{
${ }^{4}$ La cuestión feminista en María Luisa Castellanos resulta en algunos casos ambivalente. La posición que defiende la autora llanisca apoya la progresión de la mujer en las esferas públicas y en otros aspectos como el derecho al voto. Sin embargo, no renuncia al arquetipo de ángel del hogar y contribuye a un feminismo naif y burgués. En su artículo "Feminismo y sufragismo", Castellanos condena el radicalismo de las sufragistas afirmando que: "si el feminismo es emblema de la gracia, del amor, de la maternidad, de la dulzura, en cambio el sufragismo es portavoz de la vulgaridad, del desamor, del renunciamiento a la bella ilusión de tener un hijo, de la esperanza y, sobre todo, de la ausencia en la hembra, de ese perfume mujeril que la hace semejante a las rosas" (Castellanos, 1923: 31).
}

Diablotexto Digital 8 (2020), 57-78 
interesan en la cuestión feminista; nuestra acción de mutuo auxilio entre todas las mujeres, tiene como base principal la moralidad. Buscar apoyo unas en otras para mejor llevar la marcha de la existencia en esta vida de refinamientos y espiritualidades en que gravita la mujer moderna. (Castellanos, 1919b: 11)

Curiosamente, es antes de emigrar a México cuando María Luisa Castellanos se sumerge completamente en la cultura hispanoamericana. Este interés se transmite en la revista Hojas selectas a través de la sección "Escritoras americanas", en la que la llanisca escribe breves artículos sobre autoras del continente americano entre 1918 y 1920. Estas reseñas biobibliográficas permiten, en primer lugar, fomentar el diálogo y la interacción entre las letras españolas y latinoamericanas. Por otra parte, la sección contribuye a la representación femenina en una literatura seria que, por aquel entonces, era terreno vedado para la mujer (Sáez Martínez, 2008: 41). Aunque de un modo más periodístico que literario, el catálogo de autoras que propone Castellanos posee una función similar a la de los diarios de viaje, como el de la misma Eva Canel o el de la peruana Clorinda Matto de Turner, ya que "obedece también a un propósito de establecer conexiones y redes profesionales, de expandir las lecturas de su obra en los países que visita y de intentar que estos aprendan de América por el filtro de sus obras" (Meléndez, 2015: 254).

La sección recopila, en su mayor parte, autoras latinoamericanas prácticamente desconocidas para el público español. En este listado encontramos también algunas españolas como Dolores Sánchez-Granados, Carlota Remfry de Kidd, la Vizcondesa de Campo-Grande y Margarita Nelken. Mención aparte merece la asturiana María Margüelles Romano (Castellanos, 1919c), emigrada a Chile, que repite en cierto modo la historia de tránsito de nuestras autoras. La nómina de escritoras hispanoamericanas es bastante más significativa: Josefina Smith de Sanfuentes, Elena Edwards de López, Elvira Santa Cruz "Roxane", Adela Rodríguez de Rivadeneira, Sarah Hübner de Fresno "Magda Sudermann", Teresa Wilms Montt (chilenas); Luisa Pérez de Zambrana, (cubana); Elisa Ferrari (argentina); y Trinidad Padilla de Sanz "La hija del Caribe" (puertorriqueña).

Nos interesan especialmente aquellos casos en los que la llanisca pone 
de manifiesto los viajes, orígenes y residencias de estas intelectuales, en las que sus experiencias contribuyen a su brillantez literaria y conforman un marco plurinacional en el que el nomadismo supone un enriquecimiento a nivel personal y profesional. El nexo entre todas estas escritoras es una identidad fragmentada, en tanto que su vida transcurrió en un tránsito físico y espiritual constante entre España y América. Es el caso de "La hija del Caribe", tal y como apodaban a Trinidad Padilla de Sanz. La vegabajeña, avezada pianista y cuentista, se casó con el español Ángel Sanz y se trasladó a Madrid, donde se centró en su carrera musical. Fruto de esta estancia, Castellanos destaca la presencia española en sus creaciones, así como una devoción hacia España que, a grandes rasgos, se presuponía en los intelectuales latinoamericanos:

Su esposo, que era vicecónsul de España, la enseñó a amar tanto a esta patria adorada que siempre preside su hogar la bandera roja y gualda, venerada con devoción por toda aquella familia de puertorriqueños. Y puede decirse de La hija del Caribe que es un alma española dentro de una envoltura americana. (Castellanos, 1918b: 144)

En los textos de esta autora, Castellanos también destaca "ese amor a España del que ella hace tanta gala desde que supo gastar los santos amores de un español" (1918b: 144). De este tipo son varios de los ejemplos que muestra Castellanos, ya sea por motivación personal o profesional: la argentina Elisa Ferrari sigue el itinerario opuesto, viajando al Archivo de Indias sevillano "a fin de desvanecer las dudas de las que, por ignorancia y pereza de buscar por sí mismos la verdad, calumnian aún la colosal obra de la conquista americana" (1918a: 298). Con propósitos formativos emprende también la chilena Elena Edwards de López un periplo por Europa, para educarse en el arte literario y en un feminismo que, a ojos de Castellanos, es soberanamente avanzado: "desea que la mujer vaya a los comicios, gozando de los mismos derechos que el hombre en los asuntos políticos, pero sin olvidar por eso la feminidad, los deportes y las modas, que tan agradable hacen a una mujer" (1919a: 208). En lo que concierne a lo profesional, la chilena Teresa Wilms Montt es bien acogida en los círculos intelectuales madrileños. Recién llegada desde Buenos Aires, donde se había trasladado previamente tras un intento de suicidio, el destino errante de Wilms Montt constituye una muestra Diablotexto Digital 8 (2020), 57-78 
paradigmática de su alteridad como mujer transhemisférica. En otros términos, su exótica belleza fue destacada por los españoles que la conocieron y que, a pesar de todo, le rendían sus respetos por sus logros profesionales:

\footnotetext{
Los que la veían pasar esbelta y rítmica [...] se preguntaban: “¿De dónde vendrá esta belleza suprema? De otros mundos, de tras los mares." $Y$ no se equivocaban, porque Teresa venía de las transatlánticas regiones y de los mundos del ensueño, en donde vivió para un amor y subsiste por un recuerdo. (Castellanos, 1920: 6)
}

Por limitaciones espaciales, nos hemos decantado por escoger a estas autoras que, dentro del particular catálogo elaborado por Castellanos, plasman con detalle la experiencia transatlántica femenina. Lo que, a primera vista, parece un simple encargo editorial a una periodista reputada, articula un espacio de reflexión en torno a la emigración y la identidad femenina, reelaborando un marco de referencia en el que Canel, Castellanos y estas autoras pueden verse reflejadas.

\section{Conclusiones}

A través de dos autoras asturianas, hemos intentado explorar las redes de sociabilización y productividad literaria entre escritoras españolas y latinoamericanas, con el objetivo de incorporar las figuras de Eva Canel y María Luisa Castellanos a esta compleja red de sororidad y dotarlas de un mayor reconocimiento en las letras hispánicas.

Mediante las distinciones entre lo hispánico, lo latinoamericano y lo iberoamericano, se interpretan las aportaciones de Canel y Castellanos que, pese a suponer cierto progreso para la sociedad finisecular, albergan un denso filtro hispánico bajo el que el influjo español sobre América Latina es ineludible. Sus itinerarios vitales, muy similares, permitieron a estas asturianas explorar las vicisitudes de la cultura americana, especialmente en los casos de Cuba y México, países en los que se instalaron. Tomamos como punto de referencia tres ejes temáticos en los que convergen ambas autoras, tales como el dominio colonial y la influencia asturiana en América Latina, la emigración femenina como problema social de interés general, y la promoción y visibilidad de numerosas escritoras españolas y latinoamericanas que, como ellas mismas, Diablotexto Digital 8 (2020), 57-78 
se encontraron sujetas a un constante tránsito entre las dos orillas del Atlántico.

En el caso de Canel, experimentamos una paulatina transición en su posicionamiento ideológico que, tras la muerte de su marido, transitó desde el republicanismo hacia posturas más conservadoras y monárquicas. Tras el desastre del 98, la autora atenuó esta visión política en virtud de una unión armónica entre España y América. Dado su declarado, aunque paradójico, antifeminismo, y su intromisión en un mundo periodístico esencialmente gobernado por hombres, entre los enlaces de sociabilización de Canel no abundaron las mujeres, aunque no por ello dejó de aludir al talento femenino y a reivindicar la presencia de mujeres en los congresos literarios. Mención aparte merece su disertación sobre las mujeres emigrantes, cuyo análisis visibiliza un problema social transversal que, en su mayor parte, padecían mujeres transhemisféricas de menor privilegio social.

Por otra parte, Castellanos demostró en todo momento una constante defensa de las humanidades en campos como el periodismo, la literatura, la pintura o la música. De principios más progresistas que Canel, sus primeras publicaciones se centraban en un feminismo burgués que compatibilizaba la imagen pública de la mujer en diversas disciplinas y el arquetipo femenino del ángel del hogar, dedicado a los cuidados y portador de una belleza y una delicadeza definitorias del sexo. Sus aportaciones en torno a esta cuestión culminan en sus profundas reflexiones sobre la migración femenina, para la que apela a la sororidad y al principio ético de auxilio mutuo entre mujeres. Al haber nacido años después que su compatriota, Castellanos aborda la cuestión americanista a través del legado colonial en México, aunque mayor interés alberga su sección "Escritoras americanas" en la revista Hojas selectas entre 1918 y 1920. En ella, Castellanos redacta breves reseñas de escritoras latinoamericanas en las que plasma historias de mujeres en tránsito, con una vastísima vida intelectual y personal. Estas contribuciones suponen una aportación esencial para agregar nuevos elementos al complejo sistema de redes transatlánticas femeninas.

Como conclusión, observamos que estas dos asturianas, a pesar de Diablotexto Digital 8 (2020), 57-78 
haber sido relegadas a un segundo plano de los estudios literarios, ofrecieron en su día interesantísimas visiones sociales en las que el tránsito juega un papel esencial para la autorreflexión femenina. Eva Canel y María Luisa Castellanos son solamente dos de tantos estandartes femeninos que, sepultados bajo la masculinización de las letras, contribuyen a mostrar una realidad femenina construida a dos orillas del Atlántico apta para la reconstrucción de una narrativa historiográfica en la que las mujeres siempre tuvieron algo que decir.

\section{Bibliografía}

"A vuela pluma" (1898). Los Debates, 1-10-1898, p. 2

Academia de la Llingua Asturiana (s.f.). "Ixuxú". En Diccionariu de la Llingua Asturiana (DALLA).

<http://www.academiadelallingua.com/diccionariu/index.php>

[Fecha de consulta: 10 de junio de 2020].

AcostA DE SAMPER, Soledad (1895). La mujer en la sociedad moderna. París: Garnier.

Barcia ZequeIRA, María del Carmen (2001). "Eva Canel, una mujer de paradojas", Anuario de Estudios Americanos, LVIII, 1, pp. 227-252.

CANEL, Eva (1916a). La conciencia española ante el Nuevo Mundo. La Habana: Imprenta y Papelería La Universal.

Canel, Eva (1916b). Lo que vi en Cuba. La Habana: Imprenta y Papelería La Universal.

CANel, Eva (1899). De América: viajes, tradiciones y novelitas cortas. 2 volúmenes. Madrid: Establecimiento tipográfico de F. Nozal.

CANEL, Eva (1896). "Discurso leído por la distinguida escritora Eva Canel en la noche del 25 de marzo último en el Casino Español de México", El correo de Llanes (suplemento), 15-5-1896 - 10-6-1896, pp. 1-24.

CANEL, Eva (1894). Magosto: colección de tradiciones, novelas, conferencias asturianas originales. La Habana: Imprenta y Papelería La Universal.

CANEL, Eva (1887). "El congreso literario y las mujeres", El Día (Madrid), 3-101887, pp. 1-2.

Capote Díaz, Virginia; Esteban, Ángel (2017). "De Colombia a España: vidas en tránsito y escrituras migrantes". En Virginia Capote Díaz y Ángel Esteban (eds.), Escribiendo la nación, habitando España: la narrativa colombiana desde el prisma transatlántico. Madrid/Frankfurt: Iberoamericana/Vervuert, pp. 9-24.

CAstellanos, María Luisa (1928). "Desde alta mar: Asturias en América", Letras regionales (septiembre de 1928), pp. 24-25.

Castellanos, María Luisa (1923). "Feminismo y sufragismo", La Alhambra: 
revista quincenal de artes y letras (28-2-1923), pp. 30-33.

Castellanos, María Luisa (1922). "La ciudad de los palacios", La Esfera (15-41922), p. 25.

Castellanos, María Luisa (1920). "Teresa Wilms Montt”, Hojas selectas (enero de 1920), p. 6.

Castellanos, María Luisa (1919a). "Elena Edwards de López", Hojas selectas (enero de 1919), pp. 208-209.

Castellanos, María Luisa (1919b). "La emigración de la mujer", Asturias: revista gráfica semanal (28-12-1919), pp. 11-12.

Castellanos, María Luisa (1919c). "María Margüelles Romano", Hojas selectas (enero de 1919), pp. 585-586.

Castellanos, María Luisa (1918a). "La doctora Elisa Ferrari”, Hojas selectas (enero de 1918), pp. 298-299.

Castellanos, María Luisa (1918b). "La hija del Caribe”, Hojas selectas (enero de 1918), p. 144.

EpPS, Brad; FeRnÁNDEZ CIFUENTES, Luis (2005). "Introduction". En Brad Epps y Luis Fernández Cifuentes (eds.), Spain beyond Spain: Modernity, Literary History and National Identity. Lewisburg: Bucknell University Press, pp. 11-45.

FERNÁNDEZ, Pura (2015). "No hay nación para este sexo. Redes culturales de mujeres de letras españolas y latinoamericanas (1824-1936)". En Pura Fernández (ed.), No hay nación para este sexo: la $R e(d) p u ́ b l i c a$ transatlántica de las Letras: escritoras españolas y latinoamericanas (1824-1936). Madrid/Frankfurt: Iberoamericana/Vervuert, pp. 9-57.

FERRÚS ANTÓN, Beatriz (2011a). "Dos modos de narrar América Latina: autobiografía y costumbrismo en Eva Canel", Anales de Literatura Hispanoamericana, vol. 40, pp. 219-231.

FERRÚs ANTÓN, Beatriz (2011b). Mujer y literatura de viajes en el siglo XIX: entre España y las Américas. Valencia: Universidad de Valencia.

García GaLÁn, Sonia (2013). Entre la casa y la calle. Cambios socioculturales en la situación de las mujeres en Asturias (1900-1931). Tesis doctoral. Oviedo: Universidad de Oviedo.

GARCíA GALÁN, Sonia (2011). "Mujeres solteras... ¡no emigréis! Visiones de la emigración de mujeres asturianas a América 1900-1931". En María José Chivite, M. Beatriz Hernández y María Eugenia Monzón (eds.), Frontera y género: en los límites de la multidisciplinariedad. Madrid: Plaza y Valdés, pp. 187-200.

Kenmogne, Jean (1995). "Una escritora asturiana en América: Eva Canel", Cuadernos Hispanoamericanos, 546, pp. 45-61.

MACCIUCI, Raquel (2018). "El hispanismo y la literatura española en el ámbito académico latinoamericano. Una visión desde Argentina". En Rike Bolte, Jenny Haase y Susanne Schlünder (eds.), La Hispanística y los desafíos de la globalización en el siglo XXI: posiciones, negociaciones y códigos en las redes transatlánticas. Madrid/Frankfurt: Iberoamericana/Vervuert, pp. 113-130.

MELÉNDEZ, Mariselle (2015). "Geografías de conocimiento: viaje y diálogos transoceánicos en la ensayística de Clorinda Matto de Turner sobre el 
pasado colonial”. En Pura Fernández (ed.), No hay nación para este sexo: la $R e(d)$ pública transatlántica de las Letras: escritoras españolas y latinoamericanas (1824-1936). Madrid / Frankfurt: Iberoamericana/ Vervuert, pp. 247-263.

MÉNDEZ REISSIG, Ernestina (1902). Lágrimas. Montevideo: Dornaleche y Reyes Editores.

ORTEGA, Julio (2003). "Post-teoría y estudios transatlánticos", Iberoamericana, vol. III, n. ${ }^{\circ}$ 9, pp. 109-117.

Peluffo, Ana (2015). "Rizomas, redes y lazos transatlánticos: América Latina y España (1890-1920)". En Pura Fernández (ed.), No hay nación para este sexo: la $R e(d)$ pública transatlántica de las Letras: escritoras españolas y latinoamericanas (1824-1936). Madrid/Frankfurt: Iberoamericana/ Vervuert, pp. 207-224.

Picón-Febres, Gonzalo (1898). Notas y opiniones. Caracas: Tipografía Herrera Irigoyen y Cía.

PINEDO, Javier (2018). "Sobre la dimensión académica, identitaria y política del hispanismo y su relación con el latinoamericanismo". En Rike Bolte, Jenny Haase y Susanne Schlünder (eds.), La Hispanística y los desafíos de la globalización en el siglo XXI: posiciones, negociaciones y códigos en las redes transatlánticas. Madrid/Frankfurt: Iberoamericana/Vervuert, pp. 83-111.

RESINA, Joan Ramón (2018). "Los estudios ibéricos y la pérdida de función social de la literatura". En Rike Bolte, Jenny Haase y Susanne Schlünder (eds.), La Hispanística y los desafíos de la globalización en el siglo XXI: posiciones, negociaciones y códigos en las redes transatlánticas. Madrid/Frankfurt: Iberoamericana/Vervuert, pp. 63-82.

SÁEz MARTíneZ, Begoña (2008). "Críticos, críticas y criticadas: el discurso crítico ante la mujer de letras". En Pura Fernández y Marie-Linda Ortega (eds.), La mujer de letras o la letraherida: discursos y representaciones sobre la mujer escritora en el siglo XIX. Madrid: Consejo Superior de Investigaciones Científicas, pp. 33-52.

SÁNCHEZ DUEÑAS, Blas (2013). "Preocupación patriótica y compromiso nacional en las escritoras españolas finiseculares". En Carmen Servén e Ivana Rota (eds.), Escritoras españolas en los medios de prensa. 1868-1936. Sevilla: Renacimiento, pp. 237-266.

Simón PALMER, María del Carmen (2004). "Los intelectuales españoles a través del epistolario de Eva Canel y el Conde de Navas". En Antonio Cruz Casado (ed.), Bohemios, raros y olvidados. Actas del Congreso Internacional, celebrado en Lucena (Córdoba), del 4 al 7 de noviembre de 2004. Córdoba: Diputación Provincial / Ayuntamiento de Lucena, pp. 149-181.

Simón PALMER, María del Carmen (1992). "Biografía de Eva Canel" (18571932)". En Lou Charnon-Deutsch (coord.), Estudios sobre escritoras hispánicas en honor de Georgina Sabat-Rivers, Madrid: Castalia, pp. 294-304.

VÉLEZ, Palmira (2007). La historiografía americanista en España 1755-1936. Madrid/Frankfurt: Iberoamericana/Vervuert. 
Fecha de recepción: 29 de julio de 2020 .

Fecha de aceptación: 3 de octubre de 2020. 